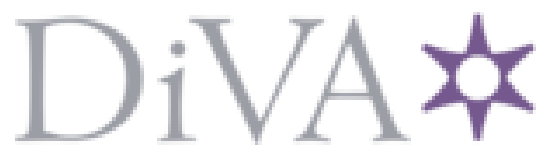

http://www.diva-portal.org

This is the published version of a paper published in Journal of oral and maxillofacial surgery (Print).

Citation for the original published paper (version of record):

Sjöström, M., Ganoo, T. (2019)

Outcomes of Maxillary Orthognathic Surgery in Patientswith Cleft Lip and Palate: A

Literature Review

Journal of oral and maxillofacial surgery (Print), 18(4): 500-508

https://doi.org/10.1007/s12663-019-01217-w

Access to the published version may require subscription.

N.B. When citing this work, cite the original published paper.

Permanent link to this version:

http://urn.kb.se/resolve?urn=urn:nbn:se:umu:diva-159668 


\title{
Outcomes of Maxillary Orthognathic Surgery in Patients with Cleft Lip and Palate: A Literature Review
}

\author{
Tulika Ganoo' $^{1}$ (D) Mats Sjöström ${ }^{1}$
}

Received: 1 June 2018/Accepted: 19 March 2019/Published online: 30 March 2019

(C) The Author(s) 2019

\begin{abstract}
Purpose Cleft lip and palate (CLP) patients often require orthognathic surgical correction due to maxillary hypoplasia secondary to primary surgeries, through either distraction osteogenesis (DO) or conventional orthognathic surgery (CO). The objective was to evaluate both surgical techniques regarding functional, aesthetics and quality-oflife and stability outcomes for the patient.

Materials and Method The PubMed database was searched with the inclusion criteria: studies in English detailing maxillary orthognathic surgery on non-syndromic patients with CLP. Clinical trials, systematic reviews, meta-analysis, reviews, randomized control trials were included. Studies with less than five patients and studies reporting bimaxillary surgery were excluded. References lists of these studies were consulted for more studies to be included. Studies were then evaluated for relevance, quality checked for risk of bias and divided based on the results studied. In total, 22 studies published between 1997 and 2017 were included.

Results Most studies had low levels of bias. The evidence to support one surgical technique before the other was low. DO offered better stability. No clear evidence exists on which technique had the best aesthetic results and functional improvement. DO may cause higher levels of anxiety and distress in patients compared to CO.
\end{abstract}

Tulika Ganoo

tulika.ganoo@umu.se

Mats Sjöström

mats.sjostrom@umu.se

1 Oral and Maxillofacial Surgery, Department of Odontology/ Faculty of Medicine, Umeå University, 90185 Umeå, Sweden
Conclusion Regarding all outcomes studied, the scrutinized literature did not allow for the recommendation of one specific technique. Future multicentre collaboration may enable greater sample size and better statistical comparison of results of both techniques.

Keywords Cleft lip and palate · Le Fort I osteotomy · Distraction osteogenesis - Conventional orthognathic surgery $\cdot$ Review

\section{Introduction}

Scarring from primary surgery for cleft lip and palate (CLP) disrupts normal maxillary growth and causes midface hypoplasia [1]. Normal mandibular growth results in a prenormal dental arch relation [2]. The retrognathic maxilla creates tendency for over-rotation of mandible resulting in pseudoprognatism, loss of facial height, class III skeletal and dental malocclusion with characteristic facial appearance and need for surgery and psychological support in teenage years [3]. Discrepancy between maxilla and mandible combined with increased vertical space between maxillary and mandibular teeth may also affect normal speech [4]. Orthodontic treatment may suffice in cases with minimal skeletal discrepancy [5]. However, when optimal occlusal relationship cannot be achieved, orthodontic treatment combined with surgery is recommended. According to some studies, up to $80 \%$ CLP patients require orthognathic surgery [3]. Orthognathic surgery, combined with orthodontics, aims to improve facial and dental aesthetics and to achieve good long-term prognosis [5].

One technique for maxillary advancement to correct class III malocclusion is conventional orthognathic surgery (CO) using Le Fort I, II or III osteotomies (LF I, II III). 
Bone grafting can be used as it may help post-operative stability and improve bone healing [5]. Another technique is distraction osteogenesis (DO) which involves an initial osteotomy to separate segments and using appliances for gradual movements. Appliances can be either placed under soft tissue cover with a small rod protruding through the skin (internal) or placed outside the skin and connected to the bone with transcutaneous pins (external) [6]. DO does not require bone grafts and can be used in patients with significant scarring from previous surgeries. In situations with significant growth abnormalities that cannot be treated with single-stage CO surgical procedure, DO can then aid treatment by gradually stretching tissues and generating new soft tissues providing long-term stability. It may also allow larger advancements with better long-term stability $[5,7]$.

The advancement that can be achieved depends on how much fibrosis is present and the patient's speech [1]. Fistulae are often present between oral and nasal regions and advancement can enlarge these or produce more [1]. Maxillary advancement causes advancement of the soft palate which can affect the velopharyngeal mechanism [5]. When the mechanism is considered borderline, orthognathic surgery can impair speech resulting in additional surgeries to improve the mechanism [4]. Risk of velopharyngeal insufficiency is present in advancement with both $\mathrm{CO}$ and DO [7]. Amount of maxillary advancement has to be limited for a patient with nasal speech [1] as velopharyngeal insufficiency affects resonance by creating nasal air escape in speech, affecting intelligibility and confidence of affected patients [3]. Thus, maxillary advancement affects facial aesthetics, function (speech and occlusion), and consequently also quality-of-life (QoL) of patients.

Therefore, it is important to evaluate (i) effects of different techniques of maxillary advancement specifically on CLP patients with developed maxillary hypoplasia secondary to primary surgery, (ii) which technique, CO or DO, offers better results, and (iii) which technique offers better stability results-lower rate of relapse.

\section{Aim}

The aim was to analyse current knowledge of different surgical techniques for maxillary advancement on CLP patients with focus on results regarding:

- facial aesthetics and stability of results achieved from surgery

- effect on function of speech and occlusion

- QoL

\section{Material and Methods}

PubMed (US National Library of Medicine, National Institutes of health) was searched on October 05, 2017, using following filters: Species: Human; Age: 'child', 'adolescent', 'adult 19 +'; Language: English. Inclusion criteria: Studies (clinical trials, systematic reviews, metaanalysis, reviews, randomized control trials) published between January 01, 1967, and October 31, 2017, (in case of to-be-published abstracts) on non-syndromic patients with CLP in journals with review system. Exclusion criteria: Studies with less than five patients and studies with bimaxillary procedures.

Search strings for aspects studied (Aesthetics, Function, Orthodontics, Stability, Surgical techniques, and QoL) were created using combinations of MeSH (Medical Subject Headings) keywords and their synonyms. Figure 1 presents a flowchart describing process for acquiring studies.

Included articles were quality-checked using an SBU (Swedish Agency for Health Technology Assessment and Assessment of Social Services) checklist (Appendix B) and checked for internal biases (treatment-, patient selection-, detection-, loss-to-follow-up-, reporting-, and conflict of interest bias) and risk-graded as low, medium, or high. Articles were summarized in protocols (Appendix C). Information noted included number and types of post-operative investigations, participant information, intervention, outcomes, reliability ratings, strength of evidence, funding, and ethical approval. To gain insight into scale of articles excluded due to bimaxillary surgery, we repeated the initial search on February 2, 2018.

\section{Results}

\section{Surgical Techniques Evaluated}

Of 22 studies, three were literature reviews and 19 clinical trials. Of 19 clinical trials, four studied CO, five studied effects of CO and DO, and 10 studied effects of DO. Eight of nine studies using CO used LF I; one did not specify technique. Three studies reporting bone grafting used autogenous bone from the iliac crest. Of 15 studies studying DO, 12 employed external distractors, three employed internal distractors, while one did not specify. One study compared two different distraction devices after LF 1: face masks and rigid external devices and thus we registered both interventions in this count. However, the authors had deemed results from the face mask unsuccessful and reverted to rigid external distraction [8]. Most of them used post-operative orthodontics. Osteotomy type was LF I $(n=10)$, LF III $(n=1)$ and not specified $(n=3)$. 


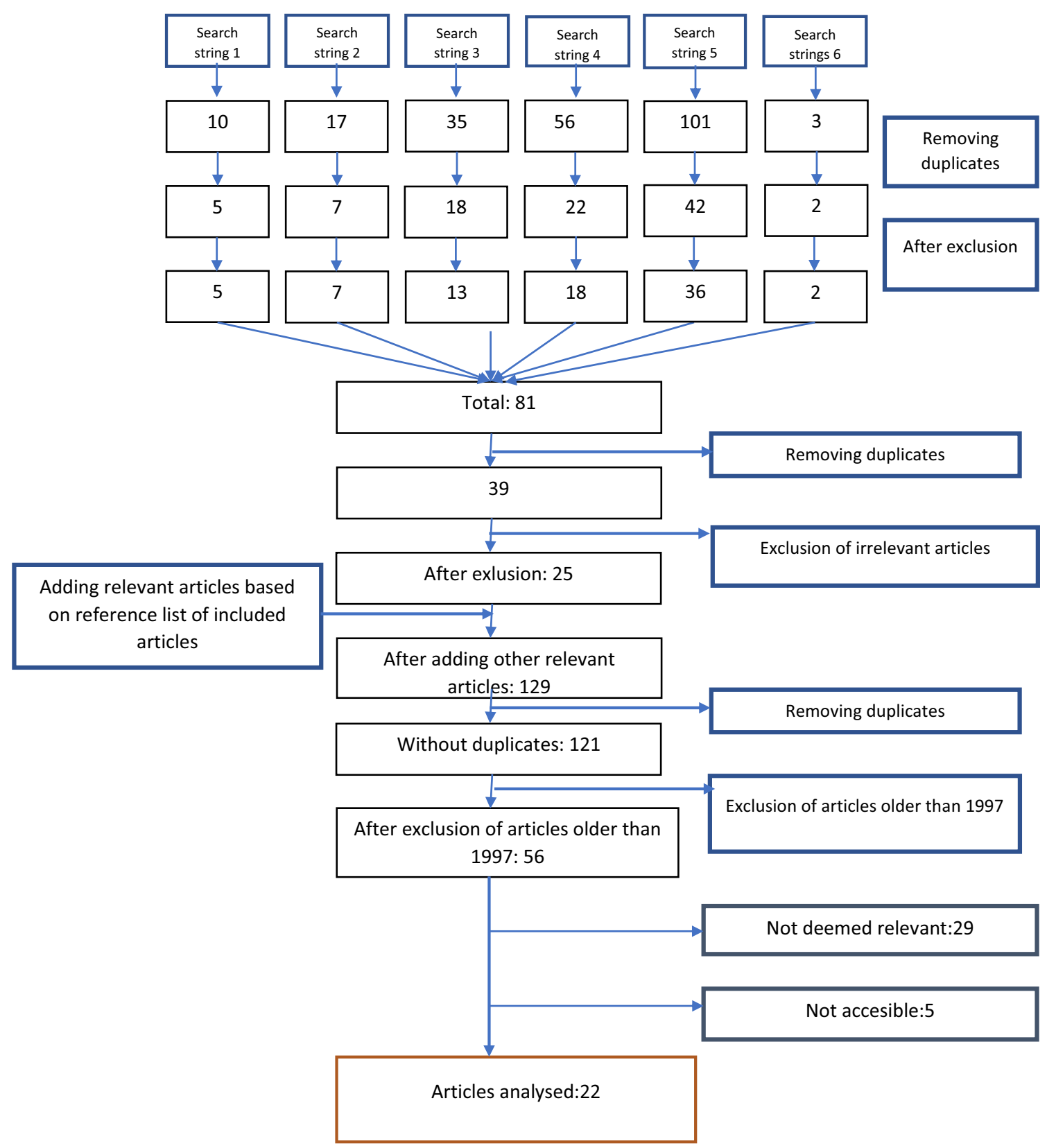

Fig. 1 Flowchart showing the process. The search strings are as follows: Esthetics (Search string 1), Function (Search string 2), Orthodontics (Search string 3), Stability (Search string 4), Surgical techniques (Search string 5), and Quality of life (Search string 6). The first row shows the total number of results obtained when results from every combination of keywords within a search category were added. The second row shows number of results per category when duplicates were removed. The third shows number of results per search category when irrelevant articles were removed. Articles were evaluated based on title and abstract. The sum of remaining articles from all search categories was 81. After duplicates were removed, 39 articles remained. Their abstracts were thoroughly scrutinized for relevance and irrelevant articles excluded leaving 25 articles. Reference lists of these 25 articles were hand searched to see if we could include more articles leading to 129 articles. However, many articles had similar references, and some were duplicates of the original 25; thus, when duplicates were excluded, total number of eligible articles were 121. The full-text articles of these 121 articles were analysed with help of the SBU (Swedish Agency for Health Technology Assessment and Assessment of Social Services) relevance checklist (Appendix A) to ensure articles were appropriate and to further confirm they pass inclusion criteria. After further discussion, we determined to exclude articles older than 20 years (1997) to make results were more relevant, leaving 56 articles. Upon further reading, 29 were excluded since they were not relevant; five were excluded since they were inaccessible, thus leaving 22 articles included in the review. Image showing the process for acquiring studies. Six search strings were used 
Results were not provided in all articles for groups with different amounts of advancement. DO was used for greater maxillary advancement.

\section{Facial Aesthetics and Stability of Surgery}

\section{Aesthetic Results}

We defined improved aesthetics as a more orthognathic frontal and side profile and good movement of soft tissue with movement of hard tissue. Orthognathic profile was defined as: frontally, the face is divided into three equal vertical parts-forehead to the eyebrow line, eyebrow line to the base of the nose (middle face), and from base of the nose to base of the chin (lower face height). One-third of lower face height is from base of the nose to the upper lip, and two-thirds from lower lip to the chin. Width of the face is equal to the distance between the eyebrow line and chin. Sagittally, a harmonious relationship with slightly convex facial flow and class I dental relationship [8]. Ten studies observed aesthetic effect. Table 1 presents study characteristics.

$\mathrm{CO}$ : significant change in maxillary position, facial convexity, and anterior facial height after anterior movement of maxilla along with corresponding movement of facial tissue and increased distinction of the nose; however, it increased nasal width and protrusion of nasal tip. Soft tissue changes were similar to non-cleft patients. DO: wellproportioned, orthognathic face with improved soft tissue profile post-operatively through counterclockwise rotation of the maxillomandibular complex (downward movement of the maxilla, moving mandible posteriorly). Even patients with severe maxillary hypoplasia had improvement in aesthetic result [9-12]. Sagittally, maxillomandibular relation normalized. Maxilla moved into a more anterior position. Maxillary length and lower facial height increased [7, 10, 13]. However, results with DO when using face mask distraction were unsuccessful according to the study authors and they switched treatment to rigid external distractor [12].

Comparing CO and DO: no statistically significant difference was seen in movement over time. Statistically significant difference in movement of hard tissue landmark at A point when comparing preoperative to six months post-op and to one-year post-op, with DO having larger movement. Most hard tissue landmarks correlated well with soft tissue parameters in the DO group [14]

\section{Stability of Results}

We defined improved stability as lower rates of relapse, maxilla maintaining its anterior position, maintained orthognathic relationship of maxilla and mandible, and maintained class I dental relationship. Studies were included if they had follow-ups at least six months post-operatively, or in case of DO, six months post-distraction. Seven studies were included. Table 2 presents study characteristics.

Within First-Year Post-Op/Distraction CO: 6-10\% horizontal relapse in first half-year post-operatively; 70/317 patients had 21-25\% vertical relapse [15]. No significant difference in relapse between $\mathrm{CO}$ and $\mathrm{DO}$ groups according to cephalometric analysis on maxillary points. Significant difference in PNS and upper incisor vertical movement in both groups [16].

One Year Post-Op/Distraction CO: Varied maxillary movement in UCLP patients; front to back in BCLP patients. [17]. Sixty of three hundred seventeen patients had 16-20\% vertical relapse [15]. DO: maxillary relapse [18], continued mandibular growth [19]. Significantly lower horizontal relapse for DO (13.4\%) compared to CO (25.5\%). Significantly less upper incisors inclination towards palatal plane in DO group (0.3 degrees) compared to $\mathrm{CO}$ group (6.7 degrees) [20].

Two Years Post-Op/Distraction CO: minor horizontal and vertical relapse [15]. DO: horizontal and vertical relapse [15, 18], continued mandibular growth, and significant decrease in divergence between maxilla and mandible [19].

Five Years Post-Op/Distraction CO: No studies obtained looking at relapse after two years. DO: Horizontal relapse posteriorly and continued mandibular growth anteriorly; however, class I relationship was maintained [19]. Five of forty-three patients that had received LF III with internal distraction developed recurrence of midface retrusion at a minimum two-year post-distraction due to lack of midface growth and received LF I osteotomy at an average seven years post-distraction [21].

\section{Effects on Quality-of-Life (QoL)}

We defined improved QoL as less negative psychological impact on patient's life. Two studies evaluated QoL. $[22,23]$. Both used social avoidance and distress scale, satisfaction with life scale and cultural-free self-esteem scale to evaluate psychological effect of DO and CO. Table 3 presents study characteristics.

Results obtained: Compared to patients with dentofacial deformities, CLP patients were happier and had higher levels of parental support; DO caused increased anxiety and distress than $\mathrm{CO}$ due to the device itself and pressure 
Table 1 Characteristics of studies: aesthetics

\begin{tabular}{|c|c|c|c|c|c|}
\hline Study & $\mathrm{CO} / \mathrm{DO}$ & $\begin{array}{l}\text { Type of } \\
\text { study }\end{array}$ & Type of patients & How outcome was observed & $\begin{array}{l}\text { Maxillary advancement } \\
(\mathrm{mm}) \text { Average (range) }\end{array}$ \\
\hline$[7]^{\mathrm{a}}$ & DO & $\mathrm{RCT}$ & $\mathrm{UCLP}+\mathrm{BCLP}+\mathrm{CP}$ & Cephalograms & $\begin{array}{l}\text { Reverse overjet } 13.5 \\
(10-15)\end{array}$ \\
\hline [17] & $\mathrm{CO}$ & Observation & $\mathrm{UCLP}+\mathrm{BCLP}+\mathrm{CP}$ & CT scans & $\begin{array}{l}\text { UCLP: } 4.69 \\
\text { BCLP: } 8 \\
\text { CP: } 7.6 \\
\text { at middle of the anterior of } \\
\text { the maxilla }\end{array}$ \\
\hline [29] & $\mathrm{CO}$ & Observation & CLP (type not specified) & Cephalometrics & $\begin{array}{l}\text { Upper Incissor Apex: } 5.15 \\
(-2.25-12.19)\end{array}$ \\
\hline$[30]$ & $\mathrm{CO}$ & Observation & $\mathrm{UCLP}+\mathrm{BCLP}+\mathrm{CP}$ & Cephalometrics & $\begin{array}{l}\text { CP: } 4.2(0.7-6.1) \\
\text { BCLP: } 5(0.2-10.7) \\
\text { UCLP:4.1 (0-8.9) }\end{array}$ \\
\hline [9] & DO & Observation & $\begin{array}{l}\mathrm{UCLP}+\mathrm{BCLP}+\mathrm{CP}+\text { Other } \\
\text { diagnoses }\end{array}$ & $\begin{array}{l}\text { Photographs, cephalograms, and dental } \\
\text { models }\end{array}$ & $\begin{array}{l}\text { Group 1: } 5 \text { (4-6), Group 2:9 } \\
(7-12)\end{array}$ \\
\hline$[10]$ & DO & Observation & $\mathrm{UCLP}+\mathrm{BCLP}$ & Cephalometrics & $\begin{array}{l}7.20 \text { measured by the dental } \\
\text { overjet }\end{array}$ \\
\hline [11] & DO & Observation & $\begin{array}{l}\mathrm{UCLP}+\mathrm{BCLP}+\mathrm{CP}+\text { Other } \\
\text { diagnoses }\end{array}$ & Cephalograms & $\begin{array}{l}6.99 \text { at } \mathrm{ANS} \text { and } 8.03 \text { at } \mathrm{A} \\
\text { point. }\end{array}$ \\
\hline [12] & DO & Observation & $\begin{array}{l}\mathrm{UCLP}+\mathrm{BCLP}+\text { Other } \\
\text { diagnoses }\end{array}$ & Cephalometry & $\begin{array}{l}\text { RED: } 11.7 \\
\text { Facemask: } 5.2\end{array}$ \\
\hline$[13]$ & DO & Observation & $\begin{array}{l}\text { UCLP + BCLP + Other } \\
\text { diagnoses }\end{array}$ & Cephalometry & 8.3 at $\mathrm{A}$ point \\
\hline$[14]^{\mathrm{a}}$ & $\mathrm{CO}+\mathrm{DO}$ & $\mathrm{RCT}$ & $\mathrm{UCLP}+\mathrm{BCLP}+\mathrm{CP}$ & Lateral cephalograms & $\begin{array}{l}\text { DO: } 6.59 \\
\text { CO: } 6.46 \text {, } \\
\text { At upper incisal tip }\end{array}$ \\
\hline$[21]^{\mathrm{a}}$ & DO & Observation & $\mathrm{UCLP}+\mathrm{BCLP}$ & $\begin{array}{l}\text { Cephalograms, computed tomographic } \\
\text { scans, full facial photographs }\end{array}$ & $\begin{array}{l}10.1(6-15) \\
\text { At the level of the zygoma }\end{array}$ \\
\hline
\end{tabular}

Table describing whether the study looked at conventional orthognathic surgery (CO) or distraction osteogenesis (DO); the type of study (where $R C T$ randomized control trial); the type of patients included where $U C L P$ unilateral cleft lip and palate, $B C L P$ bilateral cleft lip and palate, $C P$ cleft palate; the method for observing outcomes and if ethical permission was obtained

Studies that provided information regarding ethical approval are marked with superscript a

on patients and their families to correctly handle the device since they were responsible for part of the treatment. However, in long-term follow-ups patients who had received DO were more satisfied. Thus, CO offered improved QoL during treatment for patients; however, DO offered better QoL post-treatment.

\section{Effects on Function}

We defined improved functional effects as fewer cases of hypernasality, less impact on velopharyngeal (VP) area and function, reducing need for further VP surgery and improved occlusion. Eight studies focused on function. Two were systematic reviews. Five had focus either on speech results after surgery and/or on pharyngeal changes. Two analysed change in occlusion. The systematic reviews included studies with different patient compositions and techniques and included various methods for evaluating function. Table 4 presents study characteristics of the clinical studies.

\section{Effect on Speech}

CO: amount of maxillary horizontal advancement correlated with amount of nasopharyngeal airway change. Patients with previous velopharyngeoplasty (VPP) had significant post-operative change in lower nasopharyngeal airway only, despite receiving similar maxillary advancement as patients without prior VPP. Post-operatively, five patients needed VPP. For UCLP patients, moderate maxillary advancement caused significant nasopharyngeal airway changes [24]. DO: $16.7 \%$ of patients had clinically significant increase in hypernasality. $75 \%$ of patients with preoperative hyponasality experienced improved 
Table 2 Characteristics of studies: stability

\begin{tabular}{|c|c|c|c|c|c|}
\hline Study & $\mathrm{CO} / \mathrm{DO}$ & $\begin{array}{l}\text { Type of } \\
\text { study }\end{array}$ & $\begin{array}{l}\text { Type of } \\
\text { patients }\end{array}$ & $\begin{array}{l}\text { How outcome was } \\
\text { observed }\end{array}$ & Maxillary advancement (mm) average (range) \\
\hline [15] & $\mathrm{CO}+\mathrm{DO}$ & $\begin{array}{l}\text { Literature } \\
\text { review }\end{array}$ & & & $\begin{array}{l}\text { Advancement (\% of patients receiving it) CO: } 0-4(18.34 \%) \text {, } \\
5-9(36.18 \%), 10-14(4.42 \%), \text { Not mentioned }(40.97 \%) \\
\text { DO: } 0-4(2.54 \%), 5-9(42.39 \%), 10-14(8.33 \%), 15-19 \\
(1.09 \%), 20-24(0.36 \%), \text { Not mentioned }(45.29 \%)\end{array}$ \\
\hline [16] & $\mathrm{CO}+\mathrm{DO}$ & Observation & $\begin{array}{l}\text { CLP (not } \\
\text { specified } \\
\text { type) }\end{array}$ & Cephalograms & $\begin{array}{l}\text { CO: } 0-5(14.29 \%), 5-10(85.71 \%) \\
\text { DO: } 5-10(54.55 \%), 10-15(27.27 \%), 15-20(18.18)\end{array}$ \\
\hline [18] & DO & Observation & $\begin{array}{l}\text { UCLP } \\
+\mathrm{BCLP} \\
+\mathrm{CP}\end{array}$ & Cephalometrics & Average increase in the measurement of maxillary length by 9.5 \\
\hline$[19]^{\mathrm{a}}$ & DO & Observation & $\begin{array}{l}\text { UCLP } \\
+ \text { BCLP } \\
+\mathrm{CP}\end{array}$ & Cephalometrics & Mean: 11-13 measuring from skeletal points to the VL and HL \\
\hline [20] & $\mathrm{CO}+\mathrm{DO}$ & Observation & UCLP & Cephalograms & $\begin{array}{l}\text { DO: Mean } 9.8 \text { (range: } 6.5-13 \text { ) } \\
\text { CO: Mean } 5.8 \text { (range: } 4.0-7.0 \text { ) } \\
\text { At point A }\end{array}$ \\
\hline$[21]^{\mathrm{a}}$ & DO & Observation & $\begin{array}{l}\text { UCLP } \\
+ \text { BCLP }\end{array}$ & $\begin{array}{l}\text { Cephalograms, CT scans, } \\
\text { full facial photographs }\end{array}$ & $10.1(6-15)$ at the level of the zygoma \\
\hline [17] & $\mathrm{CO}$ & Observation & $\begin{array}{l}\text { UCLP } \\
+ \text { BCLP } \\
+\mathrm{CP}\end{array}$ & CT scans & $\begin{array}{l}\text { Measured at "middle" of the anterior of the maxilla UCLP: } \\
4.69 \\
\text { BCLP: } 8 \\
\text { CP: } 7.6\end{array}$ \\
\hline
\end{tabular}

Table describing whether the study looked at conventional orthognathic surgery (CO) or distraction osteogenesis (DO); the type of study; the type of patients included where $U C L P$ unilateral cleft lip and palate, $B C L P$ bilateral cleft lip and palate, $C P$ cleft palate; and the method for observing outcomes

Studies that provided information regarding ethical approval are marked with superscript a

Table 3 Characteristics of studies: the quality of life

\begin{tabular}{llllll}
\hline Study & CO/DO & $\begin{array}{l}\text { Type of } \\
\text { study }\end{array}$ & Type of patients & $\begin{array}{l}\text { How outcome was } \\
\text { observed }\end{array}$ & $\begin{array}{l}\text { Maxillary advancement } \\
(\mathrm{mm})\end{array}$ \\
\hline$[22]^{\mathrm{a}}$ & CO + DO & RCT & $\begin{array}{l}\text { 9 CLP, 9 non-cleft patients with dentofacial } \\
\text { abnormalities } \\
\text { UCLP + BCLP + CP }\end{array}$ & Questionnaires & Not specified \\
{$[23]^{\mathrm{a}}$} & CO + DO & RCT & Questionnaires & $4-10$
\end{tabular}

Table describing whether the study looked at conventional orthognathic surgery (CO) or distraction osteogenesis (DO); the type of study, where $R C T$ randomized control trial; the type of patients included where $U C L P$ unilateral cleft lip and palate, $B C L P$ bilateral cleft lip and palate, $C P$ cleft palate; and the method for observing outcomes

Studies that provided information regarding ethical approval are marked with superscript a

resonance. In most patients, there was no significant change in VP area. $67 \%$ of patients had improvement in articulation by one-year post-operative control [25]. In another study, 8/43 (19\%) patients developed hypernasality post-distraction [21].

Results of literature reviews: According to many studies, surgeries did not affect speech and VP status. According to some, worsening of speech and VP status occurred only in patients with previous VPI or previous borderline VPI [26].
Best evidence for articulation did not exist for the cleft population. Best evidence for resonance and nasalance was conflicting. Mixed best evidence for VP function based on instrument used to measure VP [27].

\section{Effect on Occlusion}

DO: In patients with less severe maxillary hypoplasia, dental relationship changed from class III occlusion, deep 
Table 4 Characteristics of studies: function

\begin{tabular}{|c|c|c|c|c|c|}
\hline Study & $\mathrm{CO} / \mathrm{DO}$ & $\begin{array}{l}\text { Type of } \\
\text { study }\end{array}$ & Type of patients & How outcome was observed & Maxillary advancement \\
\hline [9] & DO & Observation & $\begin{array}{l}\mathrm{UCLP}+\mathrm{BCLP}+\mathrm{CP}+\text { Other } \\
\text { diagnoses }\end{array}$ & Cephalograms, dental casts & 24 patients: $5(4-6), 14$ patients: $9(7-12)$ \\
\hline [10] & DO & Observation & $\mathrm{UCLP}+\mathrm{BCLP}$ & Cephalometrics & $\begin{array}{l}\text { Mean: } 7.20 \mathrm{~mm} \text { measured by the dental } \\
\text { overjet }\end{array}$ \\
\hline$[19]^{\mathrm{a}}$ & DO & Observation & $\mathrm{UCLP}+\mathrm{BCLP}+\mathrm{CP}$ & Cephalometrics & $\begin{array}{l}\text { Mean: } 11-13 \text { measuring from skeletal } \\
\text { points to the VL and HL }\end{array}$ \\
\hline$[21]^{\mathrm{a}}$ & DO & Observation & $\mathrm{UCLP}+\mathrm{BCLP}$ & $\begin{array}{l}\text { Cephalograms, CT scans, } \\
\text { speech outcome }\end{array}$ & $\begin{array}{l}\text { Average } 10.1 \text { (range, } 6 \text { to } 15 \mathrm{~mm} \text { ) at the } \\
\text { level of the zygoma }\end{array}$ \\
\hline [24] & $\mathrm{CO}$ & Observation & UCLP & Cephalograms & Mean: $4.7 \mathrm{~mm}$ \\
\hline [25] & DO & Observation & $\mathrm{UCLP}+\mathrm{BCLP}+\mathrm{CP}+$ Other & $\begin{array}{l}\text { Speech, pressure flow } \\
\text { measurements }\end{array}$ & Average: 8.7 range: $5-15$ \\
\hline [26] & $\mathrm{CO}+\mathrm{DO}$ & $\begin{array}{l}\text { Literature } \\
\text { review }\end{array}$ & & & - \\
\hline [27] & $\mathrm{CO}+\mathrm{DO}$ & $\begin{array}{l}\text { Literature } \\
\text { review }\end{array}$ & & & - \\
\hline
\end{tabular}

Table describing whether the study looked at conventional orthognathic surgery (CO) or distraction osteogenesis (DO); the type of study; the type of patients included where $U C L P$ unilateral cleft lip and palate, $B C L P$ bilateral cleft lip and palate, $C P$ cleft palate; and the method for observing outcomes

Studies that provided information regarding ethical approval are marked with superscript a

overbite, partial/total crossbite to distal sagittal molar relationship with moderate crossbite. For patients with severe hypoplasia, dental relationship changed from class III occlusion with crossbite in anterior and posterior regions and vertical skeletal open bite to either class I or class II relationship with mandibular downward, clockwise rotation [9]. Other studies too show improvement from class III to class I relationship [10], and improvement is seen five years post-op [19].

\section{Discussion}

The main outcome was: no clear-cut evidence supports $\mathrm{CO}$ or DO over the other regarding improved function and aesthetic results. The most common technique was external distraction. DO is becoming more popular based on increasing number of studies utilizing DO in recent years. Certain studies used same patients, and hence, number of studies showing a certain technique may involve risk for bias. Post-operative orthodontics were commonly added as complement to surgery and thus aesthetic and dental results attained were likely due to combination of surgical and orthodontic treatment.

\section{Implications of Results for Patients}

From patients' viewpoint, it was encouraging aesthetics improved regardless of technique. Patients should be prepared some relapse will occur. Regarding stability, DO might be preferable. QoL results during treatment suggest $\mathrm{CO}$ might be preferable. Regarding functional outcomes, good evidence DO improved occlusion. Patients must consider aesthetic benefits to effect on speech.

\section{Implications of Results for the Cleft Team}

Aesthetic and functional results mean either technique is preferable. Preoperative VP status is important to plan extent of maxillary advancement and better inform and prepare patients for hypernasality. Stability results indicated maintained inter-maxillary relations post-operatively. DO might be preferable as it has lower horizontal relapse and some evidence for being more stable. However, articles reported significant vertical relapse. When planning maxillary advancement, considering relapse is important and informing patients relapse occurs may moderate expectations and give a more realistic picture. The result that DO caused more anxiety and distress implies better information should be given. There might be differences between centres; nonetheless, it is an important consideration. Type of device (internal/external) was not specified; however, with both techniques, the patient is responsible for part of treatment. 


\section{Quality of Included Studies}

Most studies had low levels of treatment-, loss-to-followup-, reporting-, and detection bias. Most had good interexaminer reliability and used techniques which were not as sensitive to detection bias. Reasons for low loss-to-followup can be cleft patients receive long-term follow-up and undergo many procedures, ensuring good compliance.

Most studies were retrospective and conducted by surgeons/orthodontists/speech therapists involved in treatment of patients included in the study and thus risk of conflictof-interest bias. In many, inclusion criteria were not presented leading to medium risk of selection bias. Some had wide age ranges of patients (children to patients in their forties) affecting validity of result. Many had patients with different cleft diagnoses in the same group; thus, result achieved was for different cleft types. Therefore, results may not be replicable, and to see applicability of each result, it is recommended to look at the specific variable of each study. Heterogenicity between studies (different primary surgeries, different patient ethnicities, varying amounts of advancement) makes it difficult to perform a metanalysis since groups are not comparable.

Most studies did not state ethical approval. It could be because they were retrospective and hence need for ethical approval was not considered important. It is unfortunate studies looking at QoL did not specify amount of maxillary advancement as one can speculate that the greater the amount of maxillary hypoplasia, the greater the effect on QoL.

\section{Limitations of this Review}

We excluded articles using bimaxillary surgery as we wanted to focus on maxillary surgical procedures for correction of basal discrepancies and effect on aesthetics, function, QoL, and stability. However, based on one excluded study, in cases of severe maxillary hypoplasia, bimaxillary surgery should be considered [28]; thus, patients with more severe maxillary hypoplasia were probably excluded in our review. When the initial search was repeated to gain insight into scale of articles excluded due to bimaxillary surgery: $4 / 21$ articles (19\%) that seemed relevant based on title and abstract were about bimaxillary surgery procedures. Most studies did not categorize results by the amount of maxillary advancement thus limiting the scope of this article.

Other limitations include exclusion of studies that were older, not accessible, published in journals not available on PubMed (risk of publication bias) and not published in English (risk of cultural bias). Due to strict criteria, limited number of studies for most criteria evaluated and thus most results shown in this review do not have enough evidence.

\section{Future Studies}

Aspects to study in future qualitative studies are effects on QoL in patients from other cultures; if surgical relapse influences patients' QoL, and if patients feel aesthetic results and change in their QoL justified increased treatment time and effort of DO. Limitations of most included clinical trials were small sample size. Multicentre studies may enable greater sample size, and by matching patients (similar ages, similar cleft diagnoses, similar amount of maxillary advancement) but receiving $\mathrm{CO}$ or DO (depending on the centre's treatment protocol) both techniques could be statistically compared. There were no studies comparing internal and external distraction with $\mathrm{CO}$, and this could also be studied through multicentre studies. Another aspect to study is stability of CO after two-year post-op. It is also recommended that future studies divide up patients into subcategories based on the amount of maxillary advancement allowing comparison of results for different subcategories.

This review has only looked at some aspects that affect choice of surgical technique. Future studies may study other aspects such as complications, patient, and cleft team preference.

\section{Conclusion}

Most studies had limited quality due to small sample sizes and inclusion of wide age ranges and different cleft types. No clear evidence on whether conventional orthognathic (CO) surgery or distraction osteogenesis (DO) offers better functional results. DO seemed to offer better stability. Results indicate both techniques improve aesthetics, but DO caused increased anxiety and distress in patients compared to $\mathrm{CO}$. A recommendation for future is multicentre studies thus allowing possibility for greater sample sizes. Hope this review provides a base for future studies.

\section{Compliance with Ethical Standards}

Conflict of interest All authors declare that they have no conflict of interest.

Open Access This article is distributed under the terms of the Creative Commons Attribution 4.0 International License (http://crea tivecommons.org/licenses/by/4.0/), which permits unrestricted use, distribution, and reproduction in any medium, provided you give appropriate credit to the original author(s) and the source, provide a link to the Creative Commons license, and indicate if changes were made. 


\section{References}

1. Moore UJ (2011) Principles of oral and maxillofacial surgery, 6th edn. Wiley, Chichester

2. Beumer J III, Marunick MT, Esposito SJ (2011) Maxillofacial rehabilitation: prosthodontic and surgical management of cancerrelated, acquired, and congenital defects of the head and neck, 3rd edn. Quintessence Pub, Hanover Park

3. Taib BG, Taib AG, Swift AC et al (2015) Cleft lip and palate: diagnosis and management. $\mathrm{Br} \mathrm{J}$ Hosp Med Lond Engl 76:584-585

4. Shprintzen RJ, Bardach J (1995) Cleft palate speech management a multidisciplinary approach, 1st edn. Mosby, St Louis

5. Hupp JR, Tucker MR, Ellis E III et al (2014) Contemporary oral and maxillofacial surgery, 6th edn. Mosby, St Louis

6. Shah A, Danahey D (2016) Distraction osteogenesis of the maxilla treatment \& management. Medscape. https://emedicine. medscape.com/article/844742-treatment Accessed 9 Feb 2018

7. Yu H, Wang X, Fang B et al (2012) Comparative study of different osteotomy modalities in maxillary distraction osteogenesis for cleft lip and palate. J Oral Maxillofac Surg Off J Am Assoc Oral Maxillofac Surg 70:2641-2647

8. Defrancq J Orthognathic classification-facial balance. Dr Joel Defrancq Join. Worlds Funct. Aesthet. https://www.facialsculp tureclinic.com/en/surgery/orthognathic-classification/facial-bal ance/. Accessed 9 Feb 2018

9. Molina F, Monasterio FO, de la Paz Aguilar M et al (1998) Maxillary distraction: aesthetic and functional benefits in cleft lip-palate and prognathic patients during mixed dentition. Plast Reconstr Surg 101:951-963

10. Rachmiel A, Aizenbud D, Ardekian L et al (1999) Surgicallyassisted orthopedic protraction of the maxilla in cleft lip and palate patients. Int J Oral Maxillofac Surg 28:9-14

11. Ko EWC, Figueroa AA, Polley JW (2000) Soft tissue profile changes after maxillary advancement with distraction osteogenesis by use of a rigid external distraction device: a 1-year followup. J Oral Maxillofac Surg 58:959-969

12. Polley JW, Figueroa AA (1998) Rigid external distraction: its application in cleft maxillary deformities. Plast Reconstr Surg 102(5):1360-1372

13. Figueroa AA, Polley JW (1999) Management of severe cleft maxillary deficiency with distraction osteogenesis: procedure and results. Am J Orthod Dentofac Orthop Off Publ Am Assoc Orthod Its Const Soc Am Board Orthod 115:1-12

14. Chua HDP, Cheung LK (2012) Soft tissue changes from maxillary distraction osteogenesis versus orthognathic surgery in patients with cleft lip and palate-a randomized controlled clinical trial. J Oral Maxillofac Surg Off J Am Assoc Oral Maxillofac Surg 70:1648-1658

15. Cheung LK, Chua HDPP (2006) A meta-analysis of cleft maxillary osteotomy and distraction osteogenesis. Int J Oral Maxillofac Surg 35:14-24

16. Baek S-H, Lee J-K, Lee J-H et al (2007) Comparison of treatment outcome and stability between distraction osteogenesis and LeFort I osteotomy in cleft patients with maxillary hypoplasia. J Craniofac Surg 18:1209-1215

17. McCance AM, Moss JP, Fright WR et al (1997) Three-dimensional analysis techniques-Part 4: three-dimensional analysis of bone and soft tissue to bone ratio of movements in 24 cleft palate patients following Le Fort I osteotomy: a preliminary report. Cleft Palate Craniofac J 34:58-62

18. Figueroa AA, Polley JW, Friede H et al (2004) Long-term skeletal stability after maxillary advancement with distraction osteogenesis using a rigid external distraction device in cleft maxillary deformities. Plast Reconstr Surg 114:1382-1392 discussion 1393-4

19. Gürsoy S, Hukki J, Hurmerinta K (2010) Five-year follow-up of maxillary distraction osteogenesis on the dentofacial structures of children with cleft lip and palate. J Oral Maxillofac Surg 68:744-750

20. Daimaruya T, Imai Y, Kochi S et al (2010) Midfacial changes through distraction osteogenesis using a rigid external distraction system with retention plates in cleft lip and palate patients. J Oral Maxillofac Surg Off J Am Assoc Oral Maxillofac Surg 68:1480-1486

21. Hettinger PC, Hanson PR, Denny AD (2014) Le Fort III distraction using rotation advancement of the midface in patients with cleft lip and palate. Plast Reconstr Surg 134:165e-166e

22. Cheung LK, Loh JSP, Ho SMY (2006) The early psychological adjustment of cleft patients after maxillary distraction osteogenesis and conventional orthognathic surgery: a preliminary study. J Oral Maxillofac Surg Off J Am Assoc Oral Maxillofac Surg 64:1743-1750

23. Chua HDP, Ho SMY, Cheung LK (2012) The comparison of psychological adjustment of patients with cleft lip and palate after maxillary distraction osteogenesis and conventional orthognathic surgery. Oral Surg Oral Med Oral Pathol Oral Radiol 114:5-10

24. Heliövaara A, Ranta R, Hukki J et al (2002) Cephalometric pharyngeal changes after Le Fort I osteotomy in patients with unilateral cleft lip and palate. Acta Odontol Scand 60:141-145

25. Guyette TW, Polley JW, Figueroa A et al (2001) Changes in speech following maxillary distraction osteogenesis. Cleft Palate Craniofac J 38:199-205

26. Chanchareonsook N, Samman N, Whitehill TL (2006) The effect of cranio-maxillofacial osteotomies and distraction osteogenesis on speech and velopharyngeal status: a critical review. Cleft Palate Craniofac J 43:477-487

27. Pereira V, Sell D, Tuomainen J (2013) The impact of maxillary osteotomy on speech outcomes in cleft lip and palate: an evidence-based approach to evaluating the literature. Cleft Palate Craniofac J 50:25-39

28. Hirano A, Suzuki H (2001) Factors related to relapse after Le Fort I maxillary advancement osteotomy in patients with cleft lip and palate. Cleft Palate Craniofac J 38:1-10

29. Al-Waheidi EM, Harradine NW (1998) Soft tissue profile changes in patients with cleft lip and palate following maxillary osteotomies. Cleft Palate Craniofac J 35:535-543

30. Heliovaara A, Hukki J, Ranta R et al (2001) Changes in soft tissue thickness after Le Fort I osteotomy in different cleft types. Int J Adult Orthodon Orthognath Surg 16:207-213

Publisher's Note Springer Nature remains neutral with regard to jurisdictional claims in published maps and institutional affiliations. 